\title{
O "REALISMO" PLATÔNICO: UMA RESPOSTA POSSÍVEL NO FÉDON OU SOBRE A IMORTALIDADE DA ALMA
}

\author{
RACHEL GAZOLLA DE ANDRADE* \\ Departamento e Programa de Pós-Graduação em Filosofia \\ da Pontifícia Universidade Católica de São Paulo
}

\begin{abstract}
RESUMO: O texto pretende apresentar uma leitura do Fédon pouco assentada pela tradição interpretativa, e busca resgatar o Platão que se debate com as teses dos antigos fisicos e com as afirmaçôes mítico-religiosas de cunho órfico, ao invés de afirmá-las. O centro do diálogo - a imortalidade da alma - serve para que o filósofo evidencie o que é a filosofia e a separação analógica corpo-alma.
\end{abstract}

PALAVRAS-CHAVE: alma; corpo; lógos; mito; realismo; idealismo.

Realismo: 1. qualidade ou estado do que é real. 2. atitude ou posição de quem se prende fielmente ao que é real, verdadeiro...3. doutrina medieval originada na teoria das idéias de Platão, segundo a qual os universais existem por si, independentemente das coisas em que se manifestam.

Idealismo: 1. idealidade. 2. tendência, atitude ou doutrina que, em graus e sentidos diversos, reduz o ser ao pensamento ou a alguma entidade de ordem subjetiva.

(verbetes do Novo Dicionário Aurélio)

\section{Introdução: cuidados na leitura do Fédon}

O Fédon é um diálogo platônico de maturidade que poderia chamar-se "da imortalidade da alma", ou "das idéias", ou "dos contrários", ou "da participação". Guarda múltiplas vertentes de leitura, desde a histórica, no que respeita aos últimos momentos de Sócrates, passando por doutrinas e crenças diversas da 
época, até colocações extremamente abstratas da própria filosofia platônica que, já madura, deteve-se na reflexão sobre a alma. Desse modo, o estudioso do Fédon deve estar atento para discernir nesse diálogo a filosofia propriamente platônica, das outras afirmações não pertinentes a ela. Isto porque, por diversas vezes o filósofo mistura exposições diferentes da sua como se as afirmasse, mas na verdade está apenas confirmando com os discípulos as trilhas conhecidas à época sobre o difícil tema "alma e corpo", e a retomada de teses já sabidas faz parte de seu método dialógico. Em outros momentos, opta por expor e, aparentemente, aceitar o que algumas tradições mais antigas afirmam, mesmo porque um grego não deixaria de corroborá-las. Todavia, enquanto filósofo - e é este aspecto que pretendo marcar nessa palestra - ele não as endossa. Sabemos que Platão faz uso de mitos, alegorias, metáforas no intuito de melhor esclarecer uma reflexão posterior, e é preciso que o leitor saiba discernir quando o filósofo faz uso desse instrumento que, quase sempre, é possível discernir.

No Fédon, o leitor que gosta de pinçar falas pode escolher uma pertinente à alma, tendo a impressão de que o filósofo a afirma como um ser que, diferente do corpo, tem sobre ele uma ascendência imensa, uma vez que o corpo é o lugar das mais terríveis paixões e erros e seu valor é negativo. Essa é a visão mais assentada na tradição interpretativa da filosofia platônica, mas será realmente assim? Ou o sabor de tais colocações é de cunho órfico-pitagórico que, especificamente nesse diálogo, Platão faz menção por diversas vezes? Numa outra pinçada, poder-se-á acreditar no filósofo ensinando que morrendo o corpo, a alma, felizmente, vê-se livre de tão pesado fardo, podendo alçar seu vôo às regiões excelsas - um "acima", um "além" - que lhe são mais próprias e das quais foi obrigada a desligar-se. Mitos como o de Er, na República, ou aquele exposto no Górgias, bem como o do próprio Fédon, quando lidos e compreendidos literalmente, ajudam tal interpretação.

Platão, na minha opinião, retoma seitas e filosofias tradicionais baseadas em tais crenças sobre a alma, mas, ele mesmo, não as afirma, e parece que quer deixar marcada sua aproximação e sua distância delas exatamente nesse diálogo. Usa-as, sim, para preparar a sua própria reflexão como se estivesse "limpando o terreno" ao pontuar as teorias sobre a alma normalmente aceitas à época, e com isso vai levando seus dialogadores, Cebes e Símias, até onde pretende, isto é, até a abstração das idéias como fundamento do conhecimento sobre a imortalidade da alma. É o que pretendo demonstrar como sugestão de leitura, indicando um ângulo ao menos para ler-se o que posteriormente foi fixado com o nome de "realismo" platônico. É claro que o Fédon explicita pontos nucleares da filosofia 
de Platão, como o da imortalidade da alma e sua "noeticidade", também desenvolvido no Teeteto, no Timeu e no Philebo principalmente e que não é o caso de abordar neste momento.

No percurso desse difícil diálogo, difícil não só pelo conteúdo filosófico mas pelo próprio movimento de demonstração das teses que bordejam e se misturam com as imagens, tão próprias ao pensar mítico-religioso, Platão sutilmente apresenta apresenta sua concepção de "filósofo" que já delineara na República e no Banquete, diferenciando-a da imagem que sua cidade tem daqueles a quem chama usualmente com esse nome mas que ele assim não considera. Avança, ainda, algumas teses sobre o que vem a ser a alma, só aprofundadas no Timeu. Parece-me que, para um bom entendimento do Fédon, não é possível deixar de compará-lo ao Timeu, o que farei apenas em poucos momentos absolutamente necessários, dados os limites desta palestra.

Creio que os diálogos de Platão, principalmente os da maturidade, são astuciosos. O filósofo, como bom pensador da técnica, abusa das "figuras de estilo" para estruturar seu modo dialético de conduzir a alma, usa magistralmente de metáforas, alegorias e mitos para fortificar um certo mover-se do lógos que transcende - e não só no Fédon - a maiêutica socrática. Por ironia, entretanto, essa astúcia dificulta a compreensão do texto e deu margem na chamada História da Filosofia para que certos mitos e alegorias fossem lidos de modo ingênuo, porque não se levou em conta a força simbólica que Platão desenvolveu no seu lógos. Não raras vezes, a linha reflexiva de um diálogo - como aconteceu no caso do Fédon e da "Alegoria da Caverna", da República, exemplos mais lembrados foi modificada por certas interpretações tardias e sedimentaram-se como tipicamente platônicas. Sabemos que Platão às vezes é apresentado com sabor excessivamente cristão, infindáveis vezes é um cartesiano, algumas outras é espírita. No primeiro caso, basta que leiamos o demiurgo do Timeu como Deus-criador; no segundo caso, que aceitemos serem as idéias "produções" da alma; no terceiro caso, que acreditemos na saída da alma do corpo quando este morre e sua reencarnação por sucessivas vezes, até a purificação. Platão afirma todas essas teses? Não, mas não deixa de abordá-las.

Especificamente no Fédon, a linha reflexiva é tortuosa, fato que por certo propiciou a visão de um Platão radicalmente dualista, que distanciou "geograficamente" o corpo e a alma, o sensível e o inteligível, e que afirmou a existência de um mundo além deste, onde as almas vêem as verdades eternas, interpretação corroborada pela leitura linear de trechos do Ménon, por exemplo, quando Sócrates explica antigas tradições dos sacerdotes que, estas sim, afirmam o esquecimento 
das almas quanto à visão do divino. $\mathrm{O}$ mais grave, porém, parece-me ser a interpretação de que este mundo é mera cópia do mundo das idéias - e o acento está em "mera" -, de modo que cada coisa que existe é um simulacro de uma idéia, fazendo supor que nossa vida seja toda ela um simulacro havendo outro mundo modelar, tese que o próprio Platão expõe e critica no Parmênides. A questão da relação modelo-cópia aliada à noção de imitação, não é bem essa. Que se leia, atentamente, o livro IX da República.

Se Platão tivesse afirmado estas coisas, seria ele um filósofo preocupado com o ético, o político, com dúvidas quanto à possibilidade de um conhecimento verdadeiro e com as carências da linguagem? Para que utilizar-se, árdua e severamente, da força dos lógoi, de todos os seus artifícios, de seus possíveis sentidos no intuito de buscar os fundamentos do conhecer e do agir? $\mathrm{O}$ uso dos mitos não lhe é próprio, pois não é poeta, mas usá-los astuciosamente no lógos faz parte da dialética. Afinal, como ele mesmo afirma na República, ao censurar os poetas, o dizer mítico tem algo de verdadeiro. E no Fédon (61b), ele diz:

Digo-me a mim mesmo que um poeta devia, para ser verdadeiramente poeta, tomar por matéria os mitos, mas não os argumentos (mythous all'ou lógous), e também que o mitológico não me é próprio.

Mesmo cuidando de diferenciar e, ao mesmo tempo, misturar na dialogia mythos e lógos, quantas vezes é lido facilmente como órfico, isto é, da perspectiva mítico-religiosa? Se Platão foi ou não órfico, isto permanece na fronteira do possível, mas sua filosofia não é seita e não devemos ter, diante de um texto, préjulgados. O que temos de indagar ao iniciar a leitura do Fédon é: o que significa a imortalidade da alma e tudo o que a envolve, conforme a leitura do texto? Com certeza, Platão sofreu influências de seitas diversas, e é impossível negar que a crença órfica o tenha inspirado quanto à separação corpo-alma, mas inspirar não é, necessariamente, aceitar.

A seita órfica deve ter-lhe servido apenas estruturalmente, ou seja, a separação corpo-alma conforme crê o orfismo foi analogicamente usada por ele. E explico. Pouco sabemos do orfismo dado seu caráter esotérico, mas a crença na sobrevida da alma, bem como sua valorização em contraponto à desvalorização do corpo - este, prisão da alma -, é indiscutível. Através da iniciação, os crentes da seita órfica podiam distanciar, pela ascese, a alma do corpo e contatar com o divino. Ora, parece ser este o ponto que interessa a Platão, filosoficamente. 


\section{O $1^{\circ}$ compasso do Fédon: o corpo e a alma}

Platão faz na ascese dialética o mesmo que o órfico faz na sua ascese religiosa: rumo às divinas idéias, há que "deixar" o corpo para efetuar a abstração. Efetivamente, ele diz no Fédon (65 b,d):

Quando se trata de pensar (phroneseôs)? O corpo é ou não obstáculo quando, perseguindo a investigação, lhe pedimos associação? Quero dizer, afinal, isto: a vista, ou ainda o ouvido, comportam para os homens qualquer verdade? $\mathrm{Ou}$, ao menos, será que isto não se passa como até mesmo os poetas não cessam de repetir: não ouvimos nada, e nada vemos com exatidão? ... Não é no ato de arrazoar (logídzesthai), e de nenhum outro modo, que vem a manifestar-se à alma o que realmente é a coisa em questão? ... a alma arrazoa o mais perfeitamente quando não a perturbam nem a audição, nem a visão, nem a dor, nem qualquer prazer, quando ao contrário, ela se concentra o mais possível nela mesma e manda, polidamente, passear o corpo; quando, rompendo o mais de que é capaz, toda associação e todo contato com ele, ela aspira ao que é (tou ontos).

O sentido "simbólico" da separação alma-corpo é claro. Quando queremos apanhar o ser segundo ele mesmo, quando a alma pensa e arrazoa com essa finalidade, não pode estar atrelada às exigências corpóreas, mas tomada pelo movimento do lógos em busca da verdade amarra-se nela mesma, "esquecida" do corpo, ao menos "enquanto está arrazoando". E qualquer carência corpórea pode quebrar tal movimento. Se atentarmos para a diferença que Platão apresenta no Fédon entre aqueles a quem chama de gnêsíôs philosophois e que têm julgamento (dóxan) para inspirar-lhes belas palestras, e aqueles a quem chama de philomatheis, os que amam aprender, talvez essa questão fique mais clara, sutileza de linguagem que ele constrói e que costuma passar desapercebida nas traduções. Com relação aos primeiros, que ele nomeia "os filósofos de origem", expõe que o pensamento que os guia, segundo eles mesmos afirmam, é o seguinte (66 b,c):

[Dizem eles que] durante todo o tempo em que tivermos o corpo e nossa alma estiver misturada a essa coisa má, é impossível possuir suficientemente aquilo que aspiramos e, nós o afirmamos, aquilo que aspiramos é a verdade. O corpo, com efeito, é para nós fonte 
de mil problemas, pois é necessário nutri-lo; ademais, se os males sobrevêm, são obstáculos para nossa caça ao que é; os desejos, apetites, medos, simulacros de todo gênero, futilidades... por causa dele (corpo), não seria jamais possível pensar.

Mais adiante, diz sobre os que nomeia philomatheis ( $82 \mathrm{~d}, 83 \mathrm{c})$ :

É uma coisa bem conhecida dos que amam aprender: quando a filosofia toma posse de sua alma, esta se encontrava completamente acorrentada ao interior de um corpo, e como que colada a ele, obrigada, desse modo, a examinar todos os seres através dele, como das barras de uma prisão, ao invés de fazê-lo ela mesma, por ela somente, e submergindo-a, assim, na ignorância a mais total...Repito: os que amam aprender sabem bem que, no momento em que a filosofia tomou possessão de sua alma, ela se encontrava no estado em que disse; assim, a filosofia endereça à alma palavras que acalmam e inicia seu desligamento. Ela (a filosofia) lhe mostra que o caminho que consiste em examinar uma coisa por meio da vista é todo repleto de ilusões...ela persuade a alma a tomar suas distâncias...ela a convida a assemelhar-se e a dobrar-se ela mesma nela mesma...o que a alma vê, é o inteligível e o invisível...porque a alma do verdadeiro filósofo (alêthôs philosóphou psychê) crê nisso, coloca-se o quanto possível afastada dos prazeres, dos apetites, das penas, dos temores.

A diferença dessas duas colocações não deixa dúvidas. Enquanto os gnêsiôs philosóphous consideram "de fato" a separação do corpo e da alma, os philomatheis "simbolizam" tal separação na busca da verdade. Apartar o corpo da alma é persuadir através de boas palavras para que a alma inicie seu movimento de ab/ stração, ao modo da ascese do Banquete. Chegando à contemplação das idéias, o homem retorna ao concreto com outro tipo de visão, agora fundamentada porque filosófica, como abordarei mais adiante.

A alma que se "separa" do corpo coloca-o "entre parênteses", processo, aliás, repetido por Descartes quase vinte séculos depois. Separada, ela toma, nas palavras de Platão $(84, a, b)$ :

... o verdadeiro, o divino, o que não é objeto da opinião..., firmemente convencida de que assim deve viver enquanto durar sua 
vida, e que deverá, cessando de viver, juntar-se ao que lhe é aparentado e semelhante.

Aqui, um novo problema: o que significa ao ser levada pelo lógos às divinas idéias, que a alma se junte ao que lhe é aparentado, isto é, às próprias idéias? Platão responde no início do Timeu ao afirmar a alma como ousía fabricada de uma mistura de idéias contrárias, em proporções definidas. Quando é envolvida por um outro tipo de realidade - a corpórea -, ela perde o conhecimento de si mesma até que, através da educação, volte a ver-se como realmente é, uma ousía misturada, parente das idéias ${ }^{1}$. No Fédon, todavia, Platão aponta para essa relação alma-idéias mas não a desenvolve e distancia-se do tipo de morte por todos aceito, ou seja, como destruição do corpo e consequente separação da alma, para entrar na perspectiva filosófica, segundo sua própria definição de filosofia.

Lembre-se que desde Homero, a alma é pensada como sombra fugidia, espectro sem sobrevida autônoma após a morte do corpo. O corpo ao ser destruído é sêma, cadáver, e a alma perde sua potência, sua vitalidade, para tornar-se skía, sombra. Ora, a filosofia muda de registro e aceita a morte como separação almacorpo "analogicamente", como disse. Entretanto, se alguns filósofos pensam a separação vinculando-se ao pensamento mítico, ou à concepção "naturalista" da geração e corrupção dos seres, como pensam os chamados philomatheís?

\section{O $2^{\circ}$ compasso do Fédon: as teses de Cebes e Símias}

Reflexões pertinentes às escolas pré-socráticas são apresentadas na seqüência do diálogo, não mais assentadas nas antigas tradições e seitas mas referidas à não-aceitação da existência da alma após a morte do corpo. Dizem alguns que não há alma alguma que paire sobre a terra ou que vá a alguma parte, após a morte do corpo. A morte seria o perecimento absoluto do homem. Platão não especifica a quem pertencem tais teorias, mas é idéia já exposta por alguns dos primeiros "físicos", de que a physis faz e desfaz os seres, leitura que rompe qualquer laço com a tradição mítico-religiosa. Alguns intérpretes consideram que Platão visa, aqui, o atomismo de Demócrito. Diante desse novo compasso, agora argumentativo, nova postura é exigida de Platão.

Se é aceito que o filósofo é aquele que, simbolicamente, prepara-se para morrer, uma parte do terreno já está ceifada pois deixa-se para trás o pensar 
mítico-religioso. Agora, são apresentadas as demonstrações de Cebes e Símias que não podem obedecer outro critério senão o da persuasão. São, portanto, lógoi. Sucintamente, expõem os interlocutores os seguinte pontos:

1. Cebes e Símias utilizam-se de paradigmas (o arco e a lira, em Símias e o tecelão em Cebes) para fundar a impossibilidade de afirmar-se a imortalidade da alma;

2. Símias, pelo paradigma da harmonia produzida pelas cordas da lira e a posterior dissolução do instrumento indaga da sobrevivência ou não da harmonia, dissolvida a sua causa; Cebes, pelo paradigma do tecelão, de sua destruição e de seu produto em temporalidades diferentes, aponta a mesma dificuldade quanto à sobrevivência da causa do produto e do produto;

3. a idéia dos interlocutores é a de, aproximando a alma e o corpo de tais paradigmas - tanto a corda e a lira quanto a harmonia produzida, tanto o tecelão quanto as vestes que tece -, afirmar que todos perecem mesmo que em tempos diversos; no caso da harmonia, como pode ela permanecer sem o instrumento que a produz? Esse instrumento, aliás, pode durar mais que a harmonia, pois, quebrado, finda a harmonia mas não findam a madeira e cordas. Cebes indica a maior ou menor duração da vida do tecelão em comparação com a possível duração maior ou menor das vestes produzidas, para concluir que pode haver múltiplos nascimentos e mortes, que pode haver sobrevida relativa da alma ou seu perecimento, comparativamente ao corpo, e por mais que se queira não se pode demonstrar que a alma seja imortal. A alma poderá sempre deixar de existir, mesmo que permaneça além da existência do corpo, ou não (85 c a 88b).

Diante de tais lógoi, Platão terá que explicitar "logicamente" a existência da alma, e assim faz, e sua perspectiva não pode ser, agora, a da physis como ponto de geração e corrupção de todos os seres. Contrapõe à existência física à existência em lógos, marcando novo par, physis-lógos, como anteriormente marcara o par mythos-lógos. Utiliza-se, para tanto, da "lógica dos contrários" - conhecida dos interlocutores porque já desenvolvida desde os inícios da Filosofia para explicar, de outro ângulo, o movimento de geração e corrupção, substituindo a apreensão usual do "mover-se físico pelo movimento lógico". Este não necessita de qualquer comprovação exterior a ele mesmo, pois é ele próprio o núcleo comprovador de sua própria existência, é ele o movimento do pensar-dizer, numa clara alusão à aderência ser-dizer-pensar, aprofundado no Sofista. 
Estabelece, então, que sem movimento nada poderia vir-a-ser e disso ninguém discordaria. Ora, não é possível deixar de pensar no movimento senão como génesis dos contrários, o que implica aceitar que há geração de um contrário ao seu contrário e é isto que gera movimento. Assim, uma coisa maior deve conter o menor, uma coisa viva pressupõe a morta, pois como se saberia do vivo sem o morto, do maior sem o menor (70 d e seguintes)?

No entanto, mais adiante, expande a reflexão sobre os contrários apontando para a fraqueza da linguagem quanto à verdade, pois dizemos que algo é maior em relação a um menor porque ambos participam da idéia de grandeza, e dizer que Cebes é maior ou menor que Símias corresponde a uma relação estabelecida entre os dois e que se modifica se for estabelecida entre outros dois. Cebes pode ser menor que Símias e maior do que Sócrates. Logo, a grandeza da qual participa o maior e o menor não tem geração, não se forma de seu contrário, mas as coisas ditas pequenas ou grandes geram-se em função das relações que estabelecemos entre as coisas, por isso não dizemos seu ser mas dizemos sobre suas as qualidades mutáveis (103b). Todavia, há contrários dentro das coisas e contrários em si mesmos. Algumas coisas podem não aceitar os contrários, à diferença do pequeno e do grande. É o caso do fogo e da neve que não se aproximam, o mesmo acontecendo com os números pares e ímpares. Isto leva Sócrates a dizer:

Não são só as formas contrárias que não recebem seus contrários, porem há aquilo que pode carregar um contrário, qualquer que ele seja, e para o qual se pode ir (104 c).

Desse modo, o grande e o pequeno, o pesado e o leve, a vida e a morte são contrários que se geram, enquanto a coisa quente e a fria, o número par e o ímpar contêm contrários que não se geram. Compreende-se, então, que o par não gera o ímpar apesar de ser-lhe contrário, mas que o par e o ímpar são, enquanto tais, indestrutíveis, e só podem ser por existência mútua enquanto contrários. Não se pensa, portanto não "existe", o par sem o ímpar. Ora, a conclusão sobre a imortalidade da alma é facilitada com tal argumentação: ela não aceitará o contrário dela mesma pois o que torna vivo um corpo é a alma e, sendo a morte o contrário da vida, da morte a alma não se aproxima pois é princípio da vida.

Na primeira forma de geração dos contrários, Platão pensara a geração física para aproximar morte e vida. Agora, a perspectiva para não aproximar esse par contrário é a do lógos. Assim como o ímpar é indestrutível enquanto tal, pois 
não pode nascer do par apesar de depender dele para ser enquanto par (e viceversa), a alma é vida imortal e indestrutível (105 c e seguintes) e "necessita" da morte para ser pensada enquantosão tal.

Nesse lógos pouco afeito às coisas físicas, "os contrários fundam a possibilidade de conhecer e nomear as coisas que são" na medida em que julgamos a partir da participação das coisas nas idéias, isto é, nas realidades em si (lembre-se de que tais realidades estão na alma, misturadas quando do processo demiúrgico exposto no Timeu, como apontado anteriormente). Pelas idéias podemos expor os atributos e os não-atributos de algo, podemos pensá-lo em palavras. No início do Fédon, Sócrates chama a atenção para a coceira de sua perna e a ambigüidade do sentir prazer e dor. Diz do prazer de coçar que este pode provocar dor pelo excesso - um possível ferimento - ou pela ausência, o não-coçar. As palavras dor e prazer divergem, mas nas coisas físicas podem estar misturadas e nem por isso deixam de ser ditas e pensadas dentro da "lógica dos contrários". Platão, desde o início do diálogo, sabia onde iria chegar, o que comprova, também por esse viés, que o Fédon não é um diálogo com pretensões históricas como quer Burnet.

\section{O $3^{\circ}$ compasso do Fédon: a imortalidade da alma filosófica}

A sutileza da lógica platônica quanto aos contrários, aprofundada nos diálogos Sofista e Philebo, não permite que a physis aflore enquanto imagem de um vir-a-ser dos corpos. Não se trata da existência de seres físicos em movimento, pensados pela empeiría como corpos determinados; nem da "morte natural" (dissolução corpórea) não abordada por Platão nesse diálogo, mas de um lógos sobre a mudança de estado das coisas que têm parentesco com as idéias contrárias imutáveis. Uma vez mantido o devir, a morte é apenas um nome que ampara o ato de dissolução de um estado específico dos seres ditos físicos; quando algo "morre", "representamos" uma finalização. Em se tratando da morte e da vida enquanto idéias contrárias, uma não se aproxima da outra, portanto o movimento dos contrários em si mesmo é geração lógica e não cronológica.

Essa perspectiva funda o poder de conhecer e nomear propriamente platônicos, cuja condição de possibilidade está na alma como ousía misturada de idéias, como sede do nous, segundo o Timeu. Platão não é um cientista na busca daquilo de que é feita uma coisa ou do porquê de mover-se. Sendo filósofo, busca o fundamento para o pensar-dizer a coisa do modo mais verdadeiro possível. 
Esse último compasso do Fédon é o momento em que há a demonstração da influência heracliteana e parmenideana, cujo aprofundamento Platão faz no diálogo Sofista. Tanto neste diálogo quanto no Fédon há a mesma demonstração: ao mesmo tempo em que cada contrário é nele mesmo algo - o uno, o múltiplo, o movimento, o repouso, etc. -, é também gerador de seu contrário nos casos em que está em koinonía, em parentesco, sem deixar de ser ele mesmo. Não fosse assim, e não haveria qualquer possibilidade de diferenciação para pensar e falar os seres, seria a mescla originária de Anaxágoras da qual o nous está ausente, vale dizer, não teríamos alma como princípio da vida. E vida é organicidade, como afirma o filósofo no início do Timeu quando da fabricação da Alma do Mundo. Diferenciar, combinar, participar, comunicar, gerar é expressão do arrazoar e do nomear, potências da alma. Criar lógoi é pensar e expor o pensar em sentenças, em julgamentos. E não se pensa sobre o que não é, diz no Sofista.

Quanto aos "físicos", suas teses sobre a inexistência da alma após a dissolução do corpo não se sustentam logicamente, e fisicamente não se comprovam como gostariam, assim como não se comprova e não se sustenta logicamente a sua sobrevida após a morte do corpo. De bom grado, todos gostariam de ver provada qualquer das hipóteses, mas tal não é possível. Resumindo a conclusão da reflexão platônica em cinco ítens, temos:

1. é preciso buscar aquilo pelo que (aitía) a geração e a corrupção são (96a), e os lógoi são o único caminho para isso;

2. dizer aquilo pelo que, dizer a aitía, é julgar de algum modo sobre o que é, diferentemente das outras respostas sábias sobre as aitíai quando afirmam que algo é belo porque tem uma bela forma, ou porque tem o brilho do ouro, respostas que não fundam e são redundantes; dizer aquilo pelo que algo é, não é dizer o que o provocou ou do que é feito, mas é saber o que torna possível o lógos sobre ele;

3. o porquê de uma coisa tornar-se outra não está, então, na sua fragmentação (física), mas no fato de que "cada coisa torna-se algo por participar no modo de ser próprio do ser no qual veio a participar" (101c);

4. os contrários na linguagem geram-se mutuamente, como fora dito, mas alguns não podem jamais misturar-se um ao outro sem que pereçam, outros sim; já os contrários tomados em si mesmos distanciam-se porque unos, mas alguns se aproximam e geram novos contrários unos (geração lógica das idéias);

5. há coisas que, não sendo contrárias, também não se misturam, como a tríade e o par, e o par não é o contrário da tríade, mas não pode recebê-la e vice- 
versa; o mesmo com relação ao fogo e à neve, que não são contrários mas um não pode receber o outro; sendo a alma o que, entrando no corpo, lhe dá vida, ela não pode receber o seu contrário "físico" e "lingüístico", a morte, sem deixar de ser imortal e incorruptível.

Platão chega à imortalidade da alma ao demonstrar sua existência como ousía, diferente da existência corpórea composta. Se a alma fosse composta de elementos diversos (e ela é mistura de seres em-si), os elementos que a comporiam pré-existiriam a ela, portanto, se a alma é imortal e em si mesma, sempre existiu e não pode depender de nada para que venha a existir pois não tem geração (é claro que Platão, aqui, pensa na composição de elementos "físicos" diversos que podem se decompor e criar novas composições). E porque no paradigma de Símias, a harmonia não pode preexistir ou pós-existir aos elementos que a compõem, pois depende deles para existir, não é uma boa comparação para a alma. Platão chega, assim, a partir da pergunta pela aitía, a um novo enquadramento reflexivo: as aitíai do pensar-dizer são as idéias, e as coisas são cognoscíveis pelo modo de participação que têm nelas. São as idéias seres à parte dos seres físicos, como a alma é à parte do corpo. São elas a aitía, a causa, aquilo pelo que se dá o arrazoar e nomear dos seres, quer sensíveis, quer matemáticos. E não havendo lógos, isto é, não havendo arrazoamentos que "movam" os inteligíveis, temos deles a visão noética, sustentáculo para a estruturação dos lógoi.

A intenção de Platão ao recolher as crenças, doutrinas e pensamentos a respeito da alma, de sua imortalidade e de sua separação do corpo, parece-me, é a de firmar melhor sua própria perspectiva como filósofo. Fazer da filosofia um exercício de separação alma-corpo é simbolizar tal exercício como morte, marcando o perfil verdadeiro do filósofo contra os perfis que pululavam à época. Morrer filosoficamente é, como ele mesmo diz:

Examinar com toda a precisão requerida, a marcha do lógos ... na mais larga medida em que o homem for capaz de segui-lo $(107, b)$.

Finalmente, concluo com uma indagação exterior à dialética do Fédon, pertinente à historicidade: a morte de Sócrates. Platão contou-a fisicamente ao final do diálogo. Sócrates bebeu a cicuta e, após os sintomas esperados do veneno, expirou. É paradoxal essa finalização "física" depois de uma árdua argumentação "metafísica" sobre a imortalidade da alma. Talvez o Fédon, escrito anos após a morte do mestre, tenha sido a verdadeira homenagem do discípulo ao 
mestre, pois foi o Sócrates-filósofo, o Sócrates mestre do lógos que o discípulo Platão imortalizou. Sua morte corpórea existe como um novo "estado físico", do ponto de vista da geração e corrupção; não existe, afinal, para a filosofia platônica que tem "a alma socrática". E se para as representações mítico-religiosas, a alma empreende uma viagem ao despregar-se do corpo, Sócrates é imortal pois "viaja" na Histórica Ocidental até nossos dias, e mais viajará. Parece ser desse tipo a homenagem platônica ao mestre.

Ao dissolver, com astúcia, o modo como são pensados o corpo e a alma no orfismo e, em parte, por alguns que se dizem originariamente filósofos, Platão coloca o corpóreo na dimensão epistemológica, única em que lhe cabe alguma desvalorização. O corpo não é "coisa má" ou "prisão da alma", bem ao contrário, ele é parte da essência humana, apenas pode ser obstáculo à abstração. Nesse sentido, e só nesse, o corpóreo é negativo. Apesar do Fédon, do Timeu, do Sofista afirmarem um Platão não-órfico, persiste na tradição interpretativa um Platão que não encontra eco nos próprios textos. Pode-se argumentar que ele termina o Fédon com um mito, o mito das almas, confundindo o leitor com mais um mythos. Diz ele, com efeito:

Dizem que o mesmo daímon que acompanha cada um de nós durante sua vida é, também, quem conduz cada morto a um determinado lugar. Então, os que lá se encontram reunidos são submetidos a um julgamento e, imposta a sentença, são levados ao Hades (107 d).

Ora, alguém há de supor que o filósofo Platão professe de fato tal posição, que não está fazendo uso de um mito "paradigmaticamente", mesmo após ter enfrentado a tenacidade anterior de seu lógos e de sua profissão de fé na filosofia? Se Platão fica mais, ou menos, belo ao abandonar o cerne do mythos e optar pelo lógos quanto à imortalidade da alma, isto depende de cada leitor; se Platão acredita realmente na sobrevida da alma e no seu destino transmigratório, creio que jamais saberemos, mas como filósofo, não depende dela. É, de qualquer modo, instigante que ele tenha recolhido no Fédon a última fala de Sócrates, segundos antes de cerrar os olhos:

Críton, devemos um galo a Asclépio; não se esqueça dessa dívida; não seja negligente (118 a).

Sócrates talvez tenha sido um órfico, mas nada nos leva a pensar que Platão também tenha sido, ao menos nos seus textos. Mas, de bom grado, como 
ele mesmo afirma, gostaríamos de ver comprovada essa crença. Então, a alma de Sócrates viveria "fisicamente" e não apenas "logicamente".

\section{Notas}

* Professora Doutora do Departamento de Filosofia e do Programa de Pós-Graduação em Filosofia da Pontifícia Universidde Católica de São Paulo.

1 A questão do que seja a alma é difícil. Hà interpretações atuais que a consideram, segundo leitura do Timeu uma ousía matemática; outras consideram-na ousía noética porque mistura matemática sui generis - porque "lógica" e não física - de idéias supremas, portanmto, essencialmente, a alma não é forma e número matemáticos. Até o momento, tem sido essa minha posição segundo expus no livro Platão: o cosmo, o homem, a cidade (Andrade, 1992).

\section{REFERÊNCIAS BibLIOGRÁficAS}

ANDRADE, R. G. Platão: o cosmo, o homem e a cidade. Um estudo sobre a alma. Petrópolis: Editora Vozes, 1992.

BRÈS, Y. L'évoluction de la psychologie de Platon. Paris: Puf, 1973.

JOLY, H. Le renversemment platonicienne. Paris: J.Vrin, 1974.

MONTET, D. Les traits de l'être. Grenoble: Millon, 1990.

RICHARD, M.-D. L'enseignement oral de Platon. Paris: Éditions du Cerf,1986.

ANDRADE, Rachel Gazolla de. The Platonic "realism": a possible answer on the Phaedo.

ABSTRACT: The text aims at presenting a reading of the Phaedo, unusual in the interpretative tradition, and at rehabilitating the Plato who rejects the thesis of the ancient physicists as well as the Orphic mythical-religious statements instead of corroborating them. The center of the dialogue - the immortality of the soul - is used by the philosopher to demonstrate what philosophy is and the separation of body and soul.

KEYWORDS: soul; body; lógos; myth; realism; idealism. 